This is the final draft of the article published in July 2018 in Philosophy and Phenomenological Research 97 (1): 237. doi: 10.1111/phpr.12509. Please cite the published version.

\title{
PRÉCIS OF ACTION, KNOWLEDGE, AND WILL
}

Human agency has four irreducibly different dimensions-psychological, ethical, intellectual, and physical - which the traditional idea of a will tended to conflate. Examining them separately yields several significant results. First, the mark of human agency in general, like that of every kind of agent with functionally differentiated parts, is functional integration, not intention. Second, voluntariness is an ethical concept, unlike either intention or agency as such, and it is defined in negative not positive causal terms: an act is voluntary if it is not due to ignorance or compulsion, the connection between these factors being that both are normally exculpations. Third, acting intentionally cannot be defined as acting for a reason because intentional action is a manifestation of desire whereas action done for reasons is a manifestation of knowledge or belief. Furthermore, explanations that simply give agents' reasons, e.g. 'He took the left fork because it was the road to Larissa', differ significantly from ones that refer to belief, e.g. 'He took the left fork because he believed it was the road to Larissa'. For the first explanation mentions a fact about the traveller's situation he knew and took into consideration, whereas the second merely mentions his state of mind. Drawing this distinction between these different kinds of explanations leads to a new theory of knowledge as an ability that is exercised in rational thought and behaviour, and thereby a new solution to Plato's puzzle in the Meno about whether knowledge is a better guide to action than true belief. 